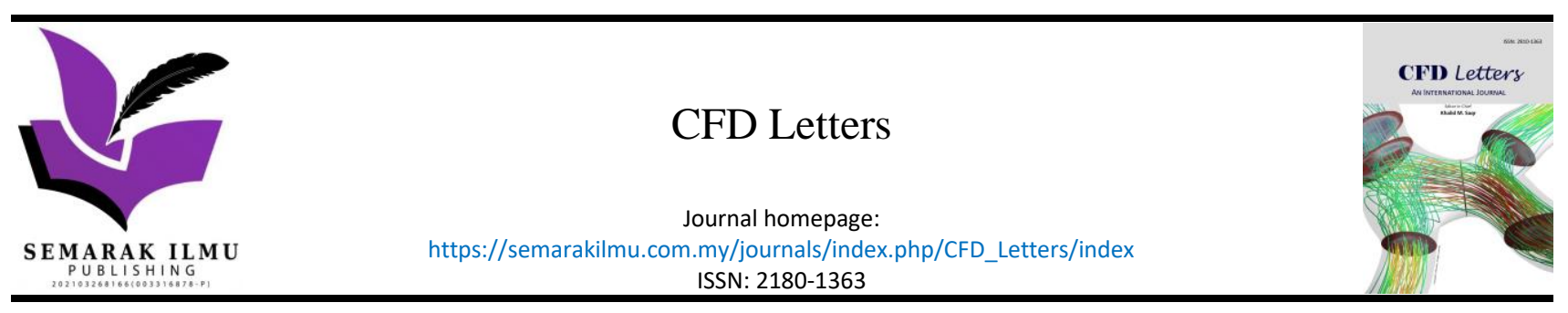

\title{
Magnetohydrodynamic Effects in Mixed Convection Copper-Water Nano Fluid Flow at Lower Stagnation Point on a Sliced Sphere
}

\author{
Basuki Widodo ${ }^{1,}$, Adhi Surya Nugraha ${ }^{2}$, Dieky Adzkiya ${ }^{1}$, Mohd Zuki Salleh $^{3}$ \\ 1 Department of Mathematics, Faculty of Sciences and Data Analytics, Institut Teknologi Sepuluh Nopember, Kampus ITS Keputih Sukolilo, 60111, \\ Surabaya, Indonesia \\ 2 Department of Mathematics Education, Faculty of Teacher Training and Education, Univesity of Sanata Dharma, Jalan Affandi, Mrican, \\ Caturtunggal, Depok Sleman, 55281, Yogyakarta, Indonesia \\ 3 Center for Mathematical Sciences, Universiti Malaysia Pahang 26300 Gambang, Kuantan, Pahang, Malaysia
}

\section{ARTICLE INFO}

Article history:

Received 4 July 2021

Received in revised form 6 November 2021

Accepted 7 November 2021

Available online 14 December 2021

\section{Keywords:}

Magnetohydrodynamic; magnetic sliced sphere; mix convection; viscous fluid; Keller-Box scheme

\section{ABSTRACT}

The study of simulation and applications of mathematics in fluid dynamics continues to grow along with the development of computer science and technology. One of them is Magnetohydrodynamics (MHD) which is closely related to its implementation in engineering and industry. And given the importance of magnetic fluid flow has attracted researchers to study and explore its benefits and uses in the industrial field, especially in convective flow and heat transfer processes. This paper therefore considers mathematical modeling on mixed convection MHD viscous fluid flow on the lower stagnation point of a magnetic sliced sphere. The study began with transforming the governing equations which are in dimensional partial differential equations to nondimensional ordinary differential equations by using the similarity variable. The resulting similarity equations are then solved by the Keller-Box scheme. The characteristics and effects of the Prandtl number, the sliced angle, the magnetic parameter, and the mixed convection parameter are analyzed and discussed. The results depicted that the uniform magnetic field produced by Lorentz force and slicing on the sphere act as determining factors for the trend of nano fluid movement and controlling the cooling rate of the sphere surface. In addition, the viscosity depends on the copper particle volume fraction.

\section{Introduction}

Several researchers have employed the MHD concept to investigate characteristics of the magnetohydrodynamic effects in mixed convection fluid flow at lower stagnation point on an object. For example the study of Yasin et al., [1] has considered numerical solution of the problem of MHD newtonian heating and thermal radiation effects $\mathrm{Fe}_{3} \mathrm{O}_{4}$ - water nano fluid flow at lower stagnation point flow on a flat plate. The problem was solved by implementing Keller box scheme. It had been obtained that the influence of significant results such as the uniform magnetic field produced from Lorentz force of the nano fluid, and heat transfer from the thermal radiation effect change in nano

* Corresponding author.

E-mail address: b_widodo@matematika.its.ac.id (Basuki Widodo) 
fluid velocity and temperature. And the fluid volume fraction affects changes in fluid viscosity. There is further another example as the study of Alkasasbeh, [2]. They had investigated the problem of convection boundary layer flow over a solid sphere of nano fluid. This problem has been solved numerically by using Keller box scheme. They had obtained that there is a correlation between the volume fraction of nanoparticles with fluid viscosity, velocity and temperature. In addition, there are also many researchers who have studied and investigated the MHD affects nano fluid flow on a body, e.g. a porous sphere [3], a horizontal circular cylinder [4], a stretching sheet [5-9], a wedge [10], a vertical flat plate [11], and a Circular Cylinder [12]. Investigation of the MHD effects in thermal convection nano fluid flow has been conducted by Choi and Eastman [13]. Further, investigation of the MHD effects in micropolar two nano fluids flow has been carried out by Nadeem et al., [14]. All the studies that I have mentioned earlier state that the heat transfer, uniform magnetic field and porosity of the object effect change in fluid velocity and temperature. And the volume fraction of the fluid affects the viscosity of the fluid. Research that has been carried out by Widodo et al., [15] considers the problem of magnetohydrodynamic effects in mixed convection viscous fluid flow at lower stagnation point on a magnetic solid sphere. The results show that the velocity and temperature of the fluid are affected by heat transfer and uniform magnetic field of the sphere.

Based on the many studies related to MHD, this motivates us to conduct research related to MHD, especially those affecting the mixed convection of copper-water nano fluid flow at the lower stagnation point on a magnetic sliced solid sphere. The dimensional equations governing this problem are further developed based on the laws of conservation of mass, momentum, and energy. The copper-water nano fluid flows from the bottom up and passes through the sliced magnetic solid sphere. The dimensional equations are then transformed into non-dimensional building equations using non-dimensional variables and then converted into a non-linear system of ordinary differential equations using flow functions and non-similar equations. This system of differential equations is then solved numerically using the Keller-Box method. Next, we discuss the effect of variations in spherical magnetic, heat transfer, volume fraction, and spherical wedge angle on changes in fluid velocity and fluid temperature above the spherical surface.

\section{Methodology}

The MHD effects in mixed convection copper- water nano fluid flow at a lower stagnation point on magnetic sliced solid sphere is considered. The copper-water nano fluid here is a solution of copper $(\mathrm{Cu})$ particles and water as the basic fluid. Mathematical model is further built from continuity equation, momentum equations, energy equation, and boundary conditions. Those equations are further converted into non-dimensional governing equation form by using non-dimensional variables and parameters. And it is obtained non-linear partial differential equations and boundary conditions. The non-linear partial differential equations are further transformed into non-linear ordinary differential equations by applying similarity equations and stream function. The resulting similarity equations are then solved by the Keller-Box scheme. The characteristics and effects of the Prandtl number, the sliced angle, the magnetic parameter, and the mixed convection parameter are analyzed and discussed.

Figure 1(a) shows the illustration of the physical model of sliced sphere and Figure 1 (b) depicts the coordinate system used. 


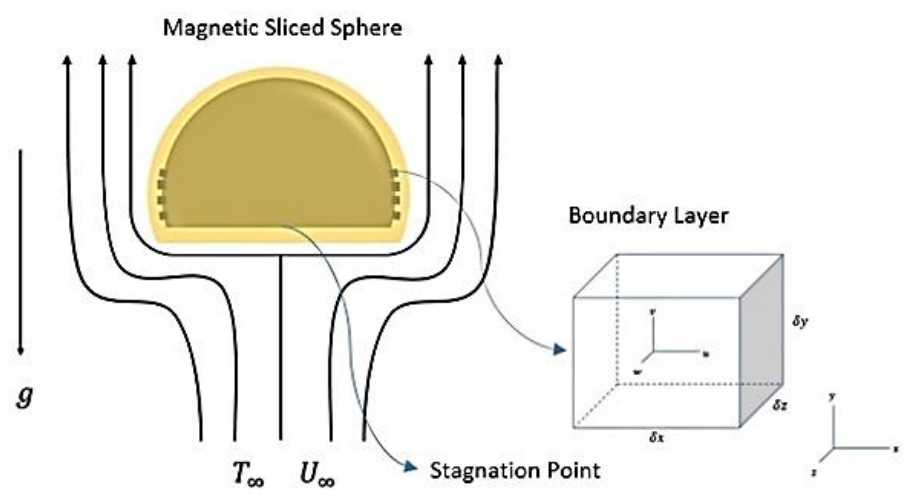

(a)

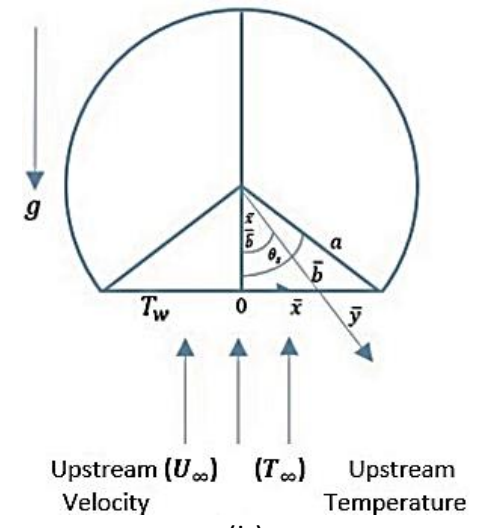

(b)

Fig. 1. (a) The physical model of sliced sphere (b) The coordinate system

The continuity equation is given by

$\frac{\partial(\bar{r} \bar{u})}{\partial \bar{x}}+\frac{\partial(\bar{r} \bar{v})}{\partial \bar{y}}=0$

The momentum equation in $x$ axis direction

$$
\left(\frac{\partial \bar{u}}{\partial \bar{t}}+\bar{u} \frac{\partial \bar{u}}{\partial \bar{x}}+\bar{v} \frac{\partial \bar{u}}{\partial \bar{y}}\right)=-\frac{\partial \bar{p}}{\partial \bar{x}}+\mu_{f n}\left(\frac{\partial^{2} \bar{u}}{\partial \bar{x}^{2}}+\frac{\partial^{2} \bar{u}}{\partial \bar{y}^{2}}\right)+\sigma\left(B_{0}-b\right)^{2} \bar{u}-\rho_{f n} \beta\left(\bar{T}-T_{\infty}\right) g \tan \left(\frac{\bar{x}}{\bar{b}}\right)
$$

The momentum equation in $y$ axis direction

$\rho_{f n}\left(\frac{\partial \bar{v}}{\partial \bar{t}}+\bar{u} \frac{\partial \bar{v}}{\partial \bar{x}}+\bar{v} \frac{\partial \bar{v}}{\partial \bar{y}}\right)=-\frac{\partial \bar{p}}{\partial \bar{y}}+\mu_{f n}\left(\frac{\partial^{2} \bar{v}}{\partial \bar{x}^{2}}+\frac{\partial^{2} \bar{v}}{\partial \bar{y}^{2}}\right)+\sigma\left(B_{0}-b\right)^{2} \bar{v}-\rho_{f n} \beta\left(\bar{T}-T_{\infty}\right) \frac{g}{\cos \left(\frac{\bar{x}}{\bar{b}}\right)}$

The energy equation is given by

$$
\left(\frac{\partial \bar{T}}{\partial \bar{t}}+\bar{u} \frac{\partial \bar{T}}{\partial \bar{x}}+\bar{v} \frac{\partial \bar{T}}{\partial \bar{y}}\right)=\alpha_{f n}\left(\frac{\partial^{2} \bar{T}}{\partial \bar{x}^{2}}+\frac{\partial^{2} \bar{T}}{\partial \bar{y}^{2}}\right)
$$

with boundary conditions as follows

$\bar{t}=0: \bar{u}=\bar{v}=0, \bar{T}=T_{\infty}$ for all positions $\bar{x}, \bar{y}$

$\bar{t}>0: \bar{u}=\bar{v}=0, \bar{T}=T_{W}$ at the $\bar{y}=0$

$\bar{u}=\frac{3}{2} U_{\infty} \sin \frac{\bar{x}}{\bar{b}}, \bar{T}=T_{\infty}$ when $\bar{y} \rightarrow \infty$

Further, it is introduced non-dimensional variables and parameters as follows [16-18]

$$
\begin{aligned}
& x=\frac{\bar{x}}{a} ; y=R e^{\frac{1}{2} \frac{\bar{y}}{a}} ; t=\frac{U_{\infty} \bar{t}}{a} ; u=\frac{\bar{u}}{U_{\infty}} ; \\
& v=\operatorname{Re}^{\frac{1}{2}} \frac{\bar{v}}{U_{\infty}} ; T=\frac{\bar{T}-T_{\infty}}{T_{W}-T_{\infty}} ; p=\frac{\bar{p}}{\rho_{f n} U_{\infty}^{2}} ;
\end{aligned}
$$




$$
\begin{aligned}
& r(x)=\frac{\bar{x}}{a} ; u_{e}(x)=\frac{\bar{u}_{e}(x)}{U_{\infty}} ; M=\frac{a \sigma\left(B_{0}-b\right)^{2}}{\rho_{f n} U_{\infty}} ; \\
& \lambda=\frac{G r}{R e^{2}} ; G r=\frac{g \beta\left(T_{W}-T_{\infty} a^{3}\right)}{v_{f n}^{2}} ; \operatorname{Pr}=\frac{v_{f n}}{v_{f}}
\end{aligned}
$$

where the Reynolds number $R e=\frac{U_{\infty}}{v_{f n}}, M$ is the magnetic parameter, $G r$ is the Grasshof number, $\operatorname{Pr}$ is the Prandtl number, and $\lambda$ is the mixed convection parameter.

By substituting those non-dimensional variables and parameters into the Eq. (1) - (4), respectively, we obtain non-dimensional governing equations as follows

The continuity equation,

$\frac{\partial(r u)}{\partial x}+\frac{\partial(r u)}{\partial y}=0$

The momentum equation in $x$ axis direction,

$\frac{\partial u}{\partial t}+u \frac{\partial u}{\partial x}+v \frac{\partial u}{\partial y}=-\frac{\partial p}{\partial x}+\frac{v_{f n}}{v_{f}} \frac{1}{R e} \frac{\partial^{2} u}{\partial x^{2}}+\frac{v_{f n}}{v_{f}} \frac{\partial^{2} u}{\partial y^{2}}++M u-\lambda T \tan \left(\frac{x \cos x}{\cos \theta_{s}}\right)$

The momentum equation in $y$ axis direction,

$\frac{1}{R e}\left(\frac{\partial v}{\partial t}+u \frac{\partial v}{\partial x}+v \frac{\partial v}{\partial y}\right)=-\frac{\partial p}{\partial y}+\frac{v_{f n}}{v_{f}} \frac{1}{R e^{2}} \frac{\partial^{2} v}{\partial x^{2}}+\frac{v_{f n}}{v_{f}} \frac{1}{R e} \frac{\partial^{2} v}{\partial y^{2}}+\frac{M}{R e} v-\frac{\lambda}{R e^{\frac{1}{2}}} \frac{T}{\cos \left(\frac{x \cos x}{\cos \theta_{s}}\right)}$

The energy equation,

$$
\left(\frac{\partial T}{\partial t}+u \frac{\partial T}{\partial x}+v \frac{\partial T}{\partial y}\right)=\frac{1}{R e} \frac{1}{P r} \frac{\alpha_{f n}}{\alpha_{f}} \frac{\partial^{2} T}{\partial x^{2}}+\frac{1}{P r} \frac{\alpha_{f n}}{\alpha_{f}} \frac{\partial^{2} T}{\partial y^{2}}
$$

Further, according to the study of Widodo et al., [15], when $R e \rightarrow \infty$ then $\frac{1}{R e} \rightarrow 0$. So the Eq. (5) - (8) can be written by the following equations, respectively.

The continuity equation,

$\frac{\partial(r u)}{\partial x}+\frac{\partial(r u)}{\partial y}=0$

The momentum equation in $\mathrm{x}$ axis direction,

$\frac{\partial u}{\partial t}+u \frac{\partial u}{\partial x}+v \frac{\partial u}{\partial y}+w \frac{\partial u}{\partial z}=-\frac{\partial p}{\partial x}+\frac{v_{f n}}{v_{f}} \frac{\partial^{2} u}{\partial y^{2}}+M u-\lambda T \tan \left(\frac{x \cos x}{\cos \theta_{s}}\right)$

The momentum equation in y axis direction,

$0=-\frac{\partial p}{\partial y}$ 
The energy equation,

$\left(\frac{\partial T}{\partial t}+u \frac{\partial T}{\partial x}+v \frac{\partial T}{\partial y}\right)=\frac{1}{P r} \frac{\alpha_{f n}}{\alpha_{f}} \frac{\partial^{2} T}{\partial y^{2}}$

For density, dynamic viscosity, specific heat, and heat conductivity of the copper-water nano fluid respectively defined as follows [2]

The nano fluid density,

$\rho_{f n}=(1-X) \rho_{f}+x \rho_{s}$

The dynamic viscosity,

$\mu_{f n}=\frac{\mu_{f}}{(1-X)^{2,5}}$

The specific heat,

$\left(\rho C_{p}\right)_{f n}=(1-X)\left(\rho C_{p}\right)_{f}+x\left(\rho C_{p}\right)_{s}$

Heat conductivity,

$\frac{k_{f n}}{k_{f}}=\frac{\left(k_{f}+2 k_{f}\right)-2 x\left(k_{f}-k_{s}\right)}{\left(k_{f}+2 k_{f}\right)+x\left(k_{f}-k_{s}\right)}$

By substituting these four equations into the Eq. (10) and (12), respectively, it is obtained non-linear partial differential equations as follows

Momentum equation in $\mathrm{x}$ axis direction,

$\frac{\partial u}{\partial t}+u \frac{\partial u}{\partial x}+v \frac{\partial u}{\partial y}+w \frac{\partial u}{\partial z}=-\frac{\partial p}{\partial x}+\left[\frac{1}{(1-X)^{2,5}\left((1-X)+X\left(\frac{\rho_{f}}{\rho_{s}}\right)\right)}\right] \frac{\partial^{2} u}{\partial y^{2}}+M u-\lambda T \tan \left(\frac{x \cos x}{\cos \theta_{s}}\right)$

and the energy equation,

$\left(\frac{\partial T}{\partial t}+u \frac{\partial T}{\partial x}+v \frac{\partial T}{\partial y}+w \frac{\partial T}{\partial z}\right)=\frac{1}{P r}\left(\frac{\left(k_{S}+2 k_{f}\right)-2 X\left(k_{f}-k_{S}\right)}{\left(\left(k_{s}+2 k_{f}\right)-2 X\left(k_{f}-k_{S}\right)\right)\left((1-X)+\left(\frac{X\left(\rho C_{p}\right)_{s}}{\left(\rho C_{p}\right)_{f}}\right)\right)}\right) \frac{\partial^{2} T}{\partial y^{2}}$

Further, these equations are transformed into non-linear ordinary differential equation by using similarity equations as follows [2]

$\psi=t^{\frac{1}{2}} u_{e}(x) ; r(x) ; f(x, \eta, t) ; \eta=\frac{y}{t^{\frac{1}{2}}} ; T=s(x, \eta, t)$ 
where $\psi$ is the stream function defined as

$u=\frac{1}{r} \frac{\partial \psi}{\partial y} ; v=-\frac{1}{r} \frac{\partial \psi}{\partial y}$

which identically satisfies the Eq. (9).

Therefore, by substituted the Eq. (14a) into the Eq. (13) and the Eq. (14), and set $x=0$ (at the lower stagnation point), the following ordinary differential equations are obtained

$\left[\frac{1}{(1-X)^{2,5}\left((1-X)+X\left(\frac{\rho_{f}}{\rho_{s}}\right)\right)}\right] \frac{\partial^{3} f}{\partial \eta^{3}}+\frac{\eta}{2} \frac{\partial^{2} f}{\partial \eta^{2}}+t \frac{3}{2}\left(\frac{1}{\cos \theta_{s}}\right)\left(1-\left(\frac{\partial f}{\partial \eta}\right)^{2}+2 f \frac{\partial^{2} f}{\partial \eta^{2}}\right)=t \frac{\partial^{2} f}{\partial t \partial \eta}+M t\left(1-\frac{\partial f}{\partial \eta}\right)-$
$\frac{2}{3} \lambda s t$

$\left(\frac{\left(k_{S}+2 k_{f}\right)-2 X\left(k_{f}-k_{s}\right)}{\left(\left(k_{S}+2 k_{f}\right)-2 X\left(k_{f}-k_{s}\right)\right)\left((1-X)+\left(\frac{X\left(\rho C_{p}\right)_{s}}{\left(\rho C_{p}\right)_{f}}\right)\right)}\right) \frac{\partial^{2} s}{\partial \eta^{2}}+\operatorname{Pr} \frac{\eta}{2} \frac{\partial s}{\partial \eta}+\frac{3}{2} \operatorname{Pr} t\left(\frac{1}{\cos \theta_{s}}\right) f \frac{\partial s}{\partial \eta}=\operatorname{Pr} t \frac{\partial s}{\partial t}$

and boundary conditions

$t=0: f=0, \frac{\partial f}{\partial \eta}=0, s=0$ for all $x, \eta$

$t>0: \frac{\partial f}{\partial \eta}=0, s=1$ at $\eta=0$

$\frac{\partial f}{\partial \eta}=1, s=0$ at $\eta \rightarrow \infty$

It should be noted that the velocity profiles and temperature distributions at the lower stagnation point of sliced sphere can be obtained from the following relations

$u=\frac{\partial f}{\partial \eta}$ and $s=s(\eta)$

The Eq. of (15) and (16) further are solved by using Keller Box method. According to the study of Widodo et al., [19], the steps are follows: firstly, reducing the order of the Eq. (15) and (16) to first order equations and then discretizing the model using finite difference method. Further, linearizing the equation by using the Newton's Method and it is obtained the algebraic equation. The last step is solving the linear system by using the technique of tridiagonal block elimination.

\section{Results}

The Keller-box method is employed to obtain the numerical solution of the Eq. (15) and (16) with the boundary conditions as in the Eq. (17) for velocity and temperature at the lower stagnation point of a sliced sphere. Then, the step size $\Delta x=\Delta \eta=0.005$ and the boundary layer thickness $\eta_{\infty}=6$ have been set throughout this investigation in the Matlab numerical codes. For the accuracy of the 
present results, it must be verified by comparing with numerical results of Ismail et al., [23]. The present results are in close agreement with the numerical results of Ismail et al., [23] for the paramaters $\lambda=1 ; \operatorname{Pr}=0: 7 ; M=0$, sliced angle $\left(\theta_{S}\right)=0^{\circ}$ and the thermophysical properties of copper-water nano particle $C u\left(\rho\left(\frac{\mathrm{kg}}{\mathrm{m}^{3}}\right)=8933 ; C p\left(\frac{\mathrm{J}}{\mathrm{kg} \mathrm{K}}\right)=385 ; k\left(\frac{\mathrm{W}}{\mathrm{mK}}\right)=400\right)$ and the Stefan-Boltzmann constant $\sigma$ have been listed in Table 1. Figure 2(a) shows the fluid velocity profiles of the present results are in close agreement with the fluid velocity profiles of Ismail et al., Figure 2(b) shows the fluid temperature profiles of the present results are also in close agreement with the fluid temperature profiles of Ismail et al.,. The present results demonstrate that the present numerical method and Matlab programme codes are accurate and effective approximate numerical method for solving this type of nonlinear problem. Further, by proceeding with numerical calculations using variations of parameters and variables that in accordance with the problem in this paper.

Table 1

Thermophysical Properties of Fluid and Nanoparticles [20-22]

\begin{tabular}{lll}
\hline Physical Properties & Fluid Phase (Water) & $\mathrm{Cu}$ \\
\hline$C_{p}(\mathrm{~J} / \mathrm{kgK})$ & 4179 & 385 \\
$\rho\left(\mathrm{kg} / \mathrm{m}^{3}\right)$ & 997.1 & 8933 \\
$k(W / \mathrm{mK})$ & 0.613 & 400 \\
$\sigma(S / \mathrm{m})$ & $5.5 \times 10^{-6}$ & $59.6 \times 10^{6}$ \\
\hline
\end{tabular}

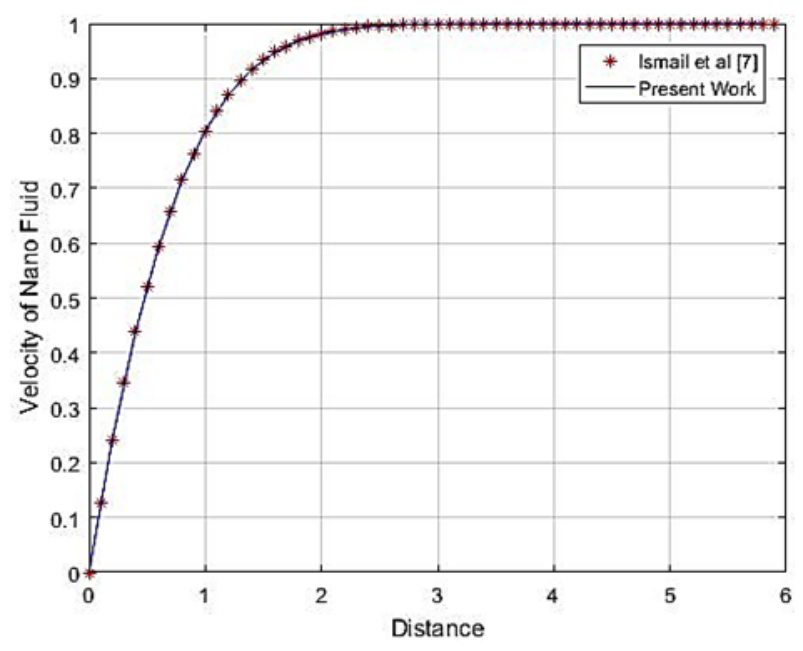

(a)

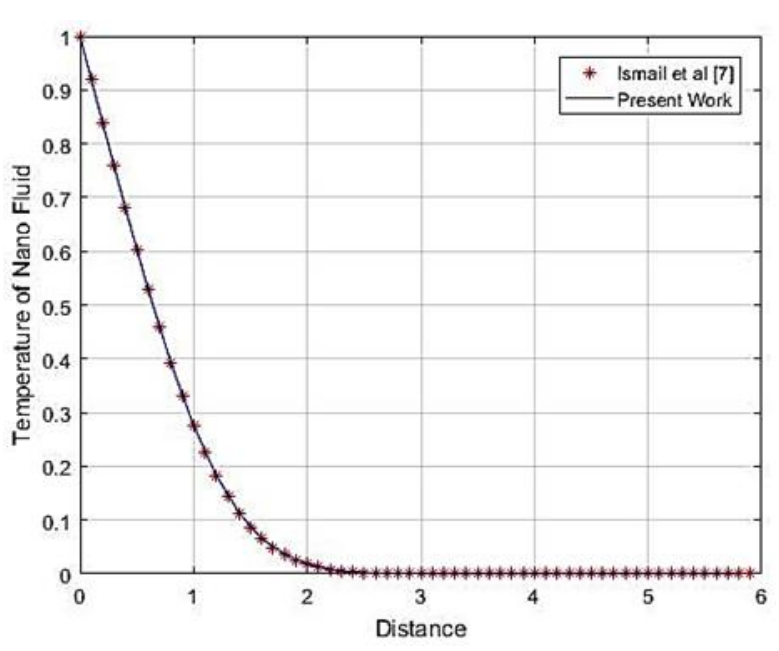

(b)

Fig. 2. (a) Velocity profile of nano fluid (b) Temperature profiles of nano fluid

The values of Prandtl number considered are $\operatorname{Pr}=0.7,1$, and 7 which correspond to air, electrolyte solution and water, respectively, according to the study of Salleh et al., [24]. Next, Table 2 shows the calculation results of the magnetic parameters if the density and the Stefan-Boltzmann constant of each Iron, cobalt, steel and zinc are given.The variation of magnetic field $(M)$ with the fixed values of $\lambda=1, \operatorname{Pr}=0.7$, sliced angle $\left(\theta_{s}\right)=30^{\circ}$, volume fraction of copper-water nano fluid $(X)=$ 0.1 , are illustrated in Figures $3(a)$ and $3(b)$. From these figures, it can be seen that an increase in magnetic parameters, $M$, leads to a decrease in fluid velocity and increase on fluid temperature. 
Table 2

Magnetic parameter values based on sphere material

\begin{tabular}{llll}
\hline Magnetic sphere & $\rho$ & $\sigma$ & $M$ \\
\hline Iron & $7.87 \times 103$ & $1.04 \times 107$ & 1.3 \\
Cobalt & $8.86 \times 103$ & $1.6 \times 107$ & 1.8 \\
Steel & $7.75 \times 103$ & $1.61 \times 107$ & 2.0 \\
Zinc & $7.14 \times 103$ & $1.68 \times 107$ & 2.4 \\
\hline
\end{tabular}

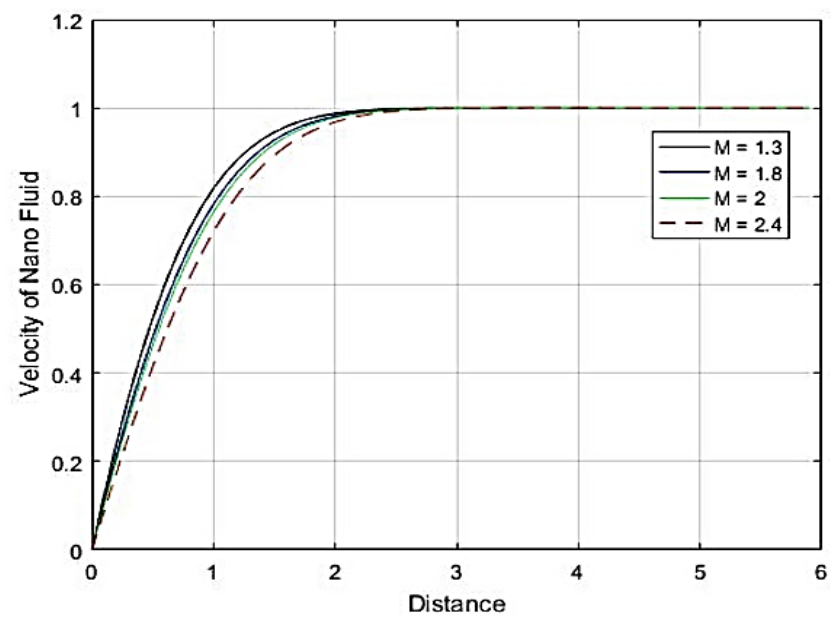

(a)

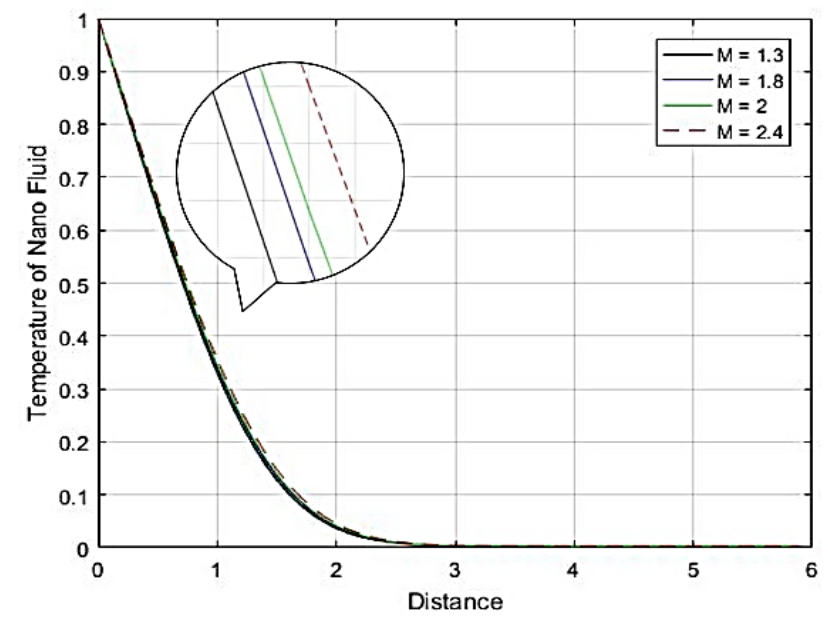

(b)

Fig. 3. (a) Fluid velocity profiles for various of magnetic parameter $(M)$ (b) Temperature curve for various of magnetic parameter $(M)$

This is expected as the presence of the Lorentz force on a magnetic sliced solid sphere creates in increase magnetic field around the magnetic sliced solid sphere. Hence, when the magnetic field parameter $(M)$ increases, so the fluid velocity decreases. Further, the uniform magnetic field produced by the magnetic sliced solid sphere will increase the internal energy of the fluid to flow, causing the temperature of the fluid increases. Hence, when the magnetic field parameter $(M)$ increases, then the fluid temperature increases. This is the same as the results of the investigation by Thirupathi et al., [25] the Radiative Magnetohydrodynamics problem of Casson Nanofluid Flow past on Nonlinear Stretching Surface.

The effect slice angle of magnetic solid sphere on the fluid velocity and temperature with the fix value of $\lambda=1, \operatorname{Pr}=0.7$, magnetic $(M)=2$, and volume fraction of nano fluid $(X)=0.1$ are shown in Figures 4(a) and 4(b). Figure 4(a) shows that an increase in slice angle of magnetic solid sphere leads to an increase in fluid velocity. This is due to the large angle of the sliced causing the area of sphere slice becomes larger and flatter. That makes the effect of the uniform magnetic field on the sphere becomes strong. Lorentz force on the sphere becomes bigger. As a result, Lorentz's strength around the sliced sphere increases. Hence, when the sliced angle $\left(\theta_{s}\right)$ parameter increases, so the fluid velocity increases. Meanwhile, the opposite behaviour was observed for the temperature profiles as shown in Figure. 4(b). This figure shows that the decrease of the fluid temperature when increasing in the slice angle of magnetic solid sphere. This is due to the large angle of the sliced of magnetic sliced solid sphere causing the area of sliced sphere becomes larger and flatter. Thus making the influence of uniform magnetic field becomes stronger. The uniform magnetic field will reduce the internal energy of the fluid causing the fluid temperature decreases. Hence, when the sliced angle of solid sphere $\left(\theta_{s}\right)$ parameter increases, then the fluid temperature decreases. 


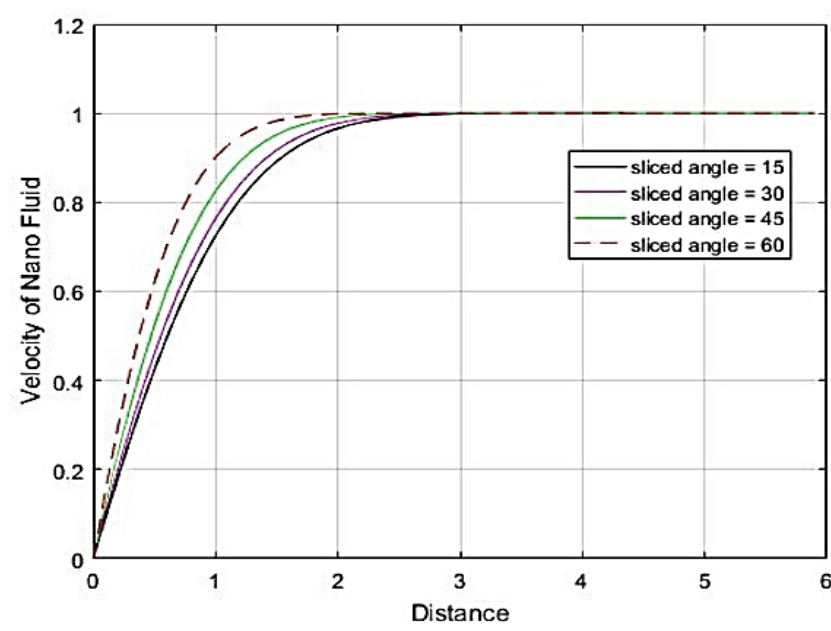

(a)

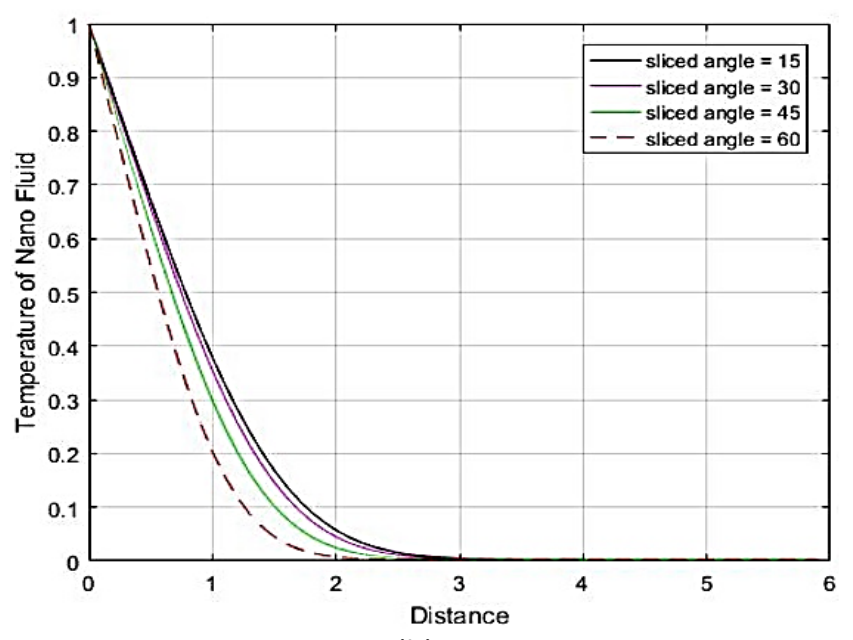

(b)

Fig. 4. (a) Fluid velocity profiles for various sliced angle of magnetic sliced solid sphere $\left(\theta_{s}\right)$ (b) Fluid temperature profiles for various sliced angle of magnetic sliced solid sphere $\left(\theta_{s}\right)$

Further, the effect volume fraction of nano fluid on the fluid velocity and temperature profiles are shown in Figure 5(a) and 5(b) respectively. These figures have been obtained when the values of $\lambda=1, \operatorname{Pr}=0.7$, magnetic $(M)=2$, and sliced angle $\left(\theta_{s}\right)=30^{\circ}$ are fixed.

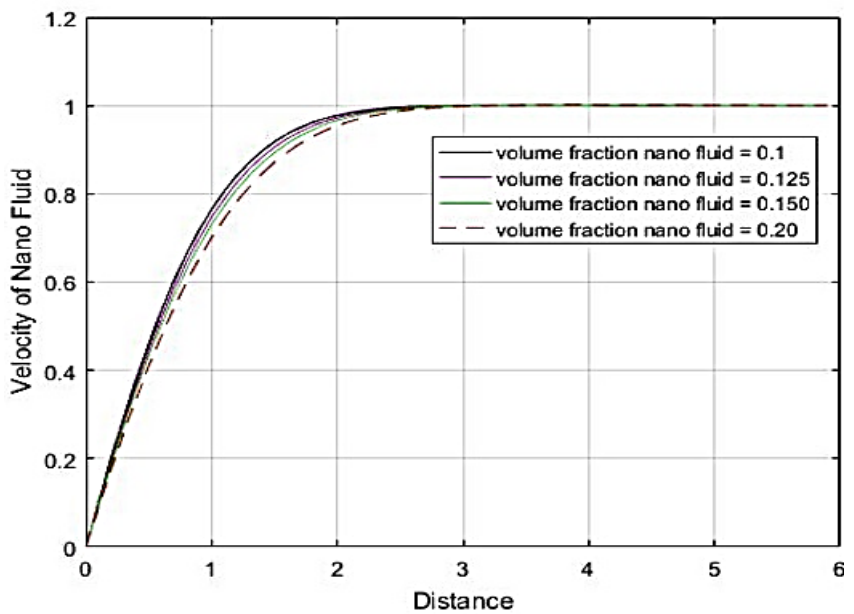

(a)

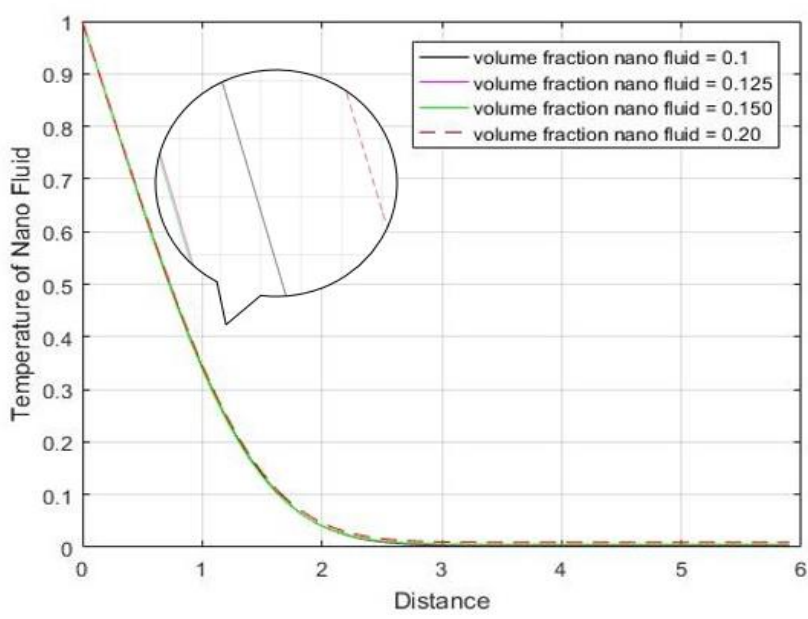

(b)

Fig. 5. (a) Fluid velocity profiles for various volume fraction $(X)$ (b) Fluid temperature profiles for various volume fraction $(X)$

Figure 5(a) shows the fluid velocity profiles influenced by various of volume fraction of nano fluid parameters. Based on variation of volume fraction of copper-water nano fluid parameters, the fluid velocity decreases when the volume fraction of the nano fluid parameter increases. This is due an increase in the volume fraction leads to an increase in number of the nano particles in the nano fluid. That causes greater friction between the particles in the fluid. Hence when the volume fraction of nano fluid $(X)$ increases, so the fluid velocity decreases.

Based on Figure 5(b), it was noticed that, the fluid temperature distributions increased when the value of volume fraction of the copper-water nano fluid parameter, $(X)$ was increased. This is expected as an increase in the volume fraction leads to an increase in number copper particles in the nano fluid. That causes friction between the particles in the fluid become greater. Large friction of 
those the copper particles can raise the temperature of the nano fluid. Hence when the volume fraction of nano fluid $(X)$ increases, then the fluid temperature increases

\section{Conclusions}

In this paper, the problem of magnetohydrodynamic effects in mixed convection fluid flow at lower stagnation point on a sliced sphere has been investigated and solved numerically. The governing boundary layer equations are transformed into a dimensionless form and the resulting nonlinear systems of partial differential equations are solved numerically using the Keller-Box method. This study has revealed how magnetic $(M)$ parameters, sliced angle of solid sphere $\left(\theta_{s}\right)$ parameters, and volume fraction $(X)$ of nano fluid parameters affect the fluid flow significantly. From the results obtained, it is revealed that

i. An increase on the values of magnetic $(M)$ parameter may lead to lower fluid velocity and raise the fluid temperature.

ii. As sliced angle of solid sphere $\left(\theta_{s}\right)$ parameter is increased, fluid velocity is increased and temperature is decreased.

iii. Velocity of the flow is reduced when volume fraction of nano fluid $(X)$ parameters is increased, and temperature of the flow is raised when volume fraction of nano fluid $(X)$ parameters is increased.

\section{Acknowledgement}

The authors would like to thank The Ministry of Education, Culture, Research, and Technology / National Research and Innovation Agency of Indonesian Republic (KEMENDIKBUDRISTEK-RI) - The Directorate for Research and Community Development (DRPM) Institut Teknologi Sepuluh Nopember Surabaya - Indonesia for funding this research.

\section{References}

[1] Yasin, Siti Hanani Mat, Muhammad Khairul Anuar Mohamed, Zulkhibri Ismail, Basuki Widodo, and Mohd Zuki Salleh. "Numerical solution on MHD stagnation point flow in ferrofluid with Newtonian heating and thermal radiation effect." CFD Letter 11, no. 2 (2019): 21- 31.

[2] Alkasasbeh, Hamzeh TS. "Numerical solution for convective boundary layer flow over a solid sphere of newtonian and non-newtonian fluid." University Malaysia Pahang (2015).

[3] Widodo, Basuki, Maulidyani Abu, and Chairul Imron. "Unsteady nano fluid flow through magnetic porous sphere under the influence of mixed convection." In Journal of Physics: Conference Series, vol. 1153, no. 1, p. 012053. IOP Publishing, 2019. https://doi.org/10.1088/1742-6596/1153/1/012053

[4] Juliyanto, Bagus, Basuki Widodo, and Chairul Imron. "The effect of heat generation on mixed convection flow in nano fluids over a horizontal circular cylinder." In Journal of Physics: Conference Series, vol. 1008, no. 1, p. 012001. IOP Publishing, 2018. https://doi.org/10.1088/1742-6596/1008/1/012001

[5] Macha, Madhu, Kishan Naikoti, and Ali J. Chamkha. "MHD flow of a non-Newtonian nanofluid over a non-linearly stretching sheet in the presence of thermal radiation with heat source/sink." Engineering Computations (2016). https://doi.org/10.1108/EC-06-2015-0174

[6] Madhu, Macha, Naikoti Kishan, and A. Chamkha. "Boundary layer flow and heat transfer of a non-Newtonian nanofluid over a non-linearly stretching sheet." International Journal of Numerical Methods for Heat \& Fluid Flow (2016). https://doi.org/10.1108/HFF-02-2015-0066

[7] Madhu, Macha, Naikoti Kishan, and Ali J. Chamkha. "Unsteady flow of a Maxwell nanofluid over a stretching surface in the presence of magnetohydrodynamic and thermal radiation effects." Propulsion and Power research 6, no. 1 (2017): 31-40. https://doi.org/10.1016/j.jppr.2017.01.002

[8] Reddy, C. Srinivas, N. Kishan, and Macha Madhu. "Finite element analysis of Eyring-Powell nano fluid over an exponential stretching sheet." International Journal of Applied and Computational Mathematics 4, no. 1 (2018): 113. https://doi.org/10.1007/s40819-017-0438-x 
[9] Madhu, Macha, and Naikoti Kishan. "Finite element analysis of MHD viscoelastic nanofluid flow over a stretching sheet with radiation." Procedia Engineering 127 (2015): 432-439. https://doi.org/10.1016/i.proeng.2015.11.393

[10] Madhu, Macha, and Naikoti Kishan. "MHD flow and heat transfer of Casson nanofluid over a wedge." Mechanics \& Industry 18, no. 2 (2017): 210. https://doi.org/10.1051/meca/2016030

[11] Mohamed, Muhammad Khairul Anuar, Huei Ruey Ong, Mohd Zuki Salleh, and Basuki Widodo. "Mixed convection boundary layer flow of engine oil nanofluid on a vertical flat plate with viscous dissipation." Asean Journal of Automotive Technology 1, no. 1 (2019): 29-38.

[12] Ismail, M. A., N. F. Mohamad, M. R. Ilias, and S. Shafie. "MHD Effect on Unsteady Mixed Convection Boundary Layer Flow past a Circular Cylinder with Constant Wall Temperature." In Journal of Physics: Conference Series, vol. 890, no. 1, p. 012054. IOP Publishing, 2017. https://doi.org/10.1088/1742-6596/890/1/012054

[13] Choi, S. US, and Jeffrey A. Eastman. Enhancing thermal conductivity of fluids with nanoparticles. No. ANL/MSD/CP84938; CONF-951135-29. Argonne National Lab., IL (United States), 1995.

[14] Nadeem, S., Z. Ahmed, and S. Saleem. "The effect of variable viscosities on micropolar flow of two nanofluids." Zeitschrift für Naturforschung A 71, no. 12 (2016): 1121-1129. https://doi.org/10.1515/zna-2015-0491

[15] Widodo, Basuki, Lutfi Mardianto, and Dieky Adzkiya. "Numerical investigation on magnetohydrodynamics mixed convection flow past a magnetic sphere." In Journal of Physics: Conference Series, vol. 1153, no. 1, p. 012059. IOP Publishing, 2019. https://doi.org/10.1088/1742-6596/1153/1/012059

[16] Widodo, B., I. Anggriani, and C. Imron. "The Characterization Of Boundary Layer Flow in The Magnetohydrodynamic Micropolar Fluid Past A Solid Sphere." International Journal of Advances in Science Engineering and Technology, ISSN (2016): 2321-9009.

[17] Blas, Nikki, and Guido David. "Dynamical roguing model for controlling the spread of tungro virus via Nephotettix Virescens in a rice field." In Journal of Physics: Conference Series, vol. 893, no. 1, p. 012018. IOP Publishing, 2017. https://doi.org/10.1088/1742-6596/893/1/012018

[18] Nugraha, A. S., B. Widodo, and C. Imron. "Unsteady magnetohydrodynamics of viscous fluid past a magnetic sliced sphere." In AIP Conference Proceedings, vol. 2242, no. 1, p. 030007. AIP Publishing LLC, 2020. https://doi.org/10.1063/5.0007930

[19] Widodo, B., D. A. Khalimah, F. D. S. Zainal, and C. Imron. "The effect of Prandtl number and magnetic parameter on forced convection unsteady magnetohydrodynamics boundary layer flow of a viscous fluid past a sphere." In International Conference on Science and Innovative Engineering (ICSIE). 2015.

[20] Kuznetsov, A. V., and D. A. Nield. "Natural convective boundary-layer flow of a nanofluid past a vertical plate: A revised model." International journal of thermal sciences $77 \quad$ (2014): $126-129$. https://doi.org/10.1016/j.ijthermalsci.2013.10.007

[21] Mutuku-Njane, Winifred Nduku, and Oluwole Daniel Makinde. "Combined effect of Buoyancy force and Navier slip on MHD flow of a nanofluid over a convectively heated vertical porous plate." The Scientific World Journal 2013 (2013). https://doi.org/10.1155/2013/725643

[22] Kho, Yap Bing, Rahimah Jusoh, Mohd Zuki Salleh, Muhammad Khairul Anuar Mohamed, Zulkhibri Ismail, and Rohana Abdul Hamid. "Inclusion of Viscous Dissipation on the Boundary Layer Flow of Cu-TiO2 Hybrid Nanofluid over Stretching/Shrinking Sheet." Journal of Advanced Research in Fluid Mechanics and Thermal Sciences 88, no. 2 (2021): 64-79. https://doi.org/10.37934/arfmts.88.2.6479

[23] Ismail, Mohamad Alif, Nurul Farahain Mohammad, and Sharidan Shafie. "Separation time analysis of transient magnetohydrodynamic mixed convection flow of nanofluid at lower stagnation point past a sphere." Malaysian Journal of Fundamental and Applied Sciences 13, no. 3 (2017): 151-154. https://doi.org/10.11113/mjfas.v13n3.637

[24] Salleh, M. Z., R. Nazar, and I. Pop. "Mixed convection boundary layer flow from a solid sphere with Newtonian heating in a micropolar fluid." SRX Physics 2010 (2010). https://doi.org/10.3814/2010/736039

[25] Thirupathi, Gurrala, Kamatam Govardhan, and Ganji Narender. "Radiative Magnetohydrodynamics Casson Nanofluid Flow and Heat and Mass Transfer past on Nonlinear Stretching Surface." Beilstein Archives 2021, no. 1 (2021): 65. https://doi.org/10.3762/bxiv.2021.65.v1 